\title{
Maternal and neonatal outcomes of COVID-19 in a high-risk pregnant cohort with and without HIV
}

\author{
L de Waard, ${ }^{1}$ FCOG; E Langenegger, ${ }^{1}$ PhD; K Erasmus, ${ }^{1} \mathrm{MB}$ ChB; T van der Merwe, ${ }^{1}$ FCOG; S E Olivier, ${ }^{1}$ MB ChB; \\ N du Toit, ${ }^{1}$ MB ChB; C Paulsen, ${ }^{1}$ FCOG; N Nkangana, ${ }^{1}$ MB ChB; M van Niekerk, ${ }^{2}$ FC Paeds (SA); A Moodley, ${ }^{1}$ FCOG; S Schell, ${ }^{1}$ Dip Nurs; \\ J Taljaard, ${ }^{3}$ MMed (Int Med); M H Botha, ${ }^{1} \mathrm{PhD}$; A Dramowski, ${ }^{2} \mathrm{PhD}$; C A Cluver, ${ }^{1,45} \mathrm{PhD} ; \mathbf{A}$ Bekker, ${ }^{2} \mathrm{PhD}$ \\ ${ }^{1}$ Department of Obstetrics and Gynaecology, Faculty of Medicine and Health Sciences, Stellenbosch University, Cape Town, South Africa \\ ${ }^{2}$ Department of Paediatrics and Child Health, Faculty of Medicine and Health Sciences, Stellenbosch University, Cape Town, South Africa \\ ${ }^{3}$ Division of Infectious Diseases, Tygerberg Hospital and Department of Medicine, Faculty of Medicine and Health Sciences, Stellenbosch \\ University, Cape Town, South Africa \\ ${ }^{4}$ Translational Obstetrics Group, Department of Obstetrics and Gynaecology, Faculty of Medicine, Dentistry and Health Sciences, University of \\ Melbourne, Victoria, Australia \\ ${ }^{5}$ Mercy Perinatal, Mercy Hospital for Women, Heidelberg, Victoria, Australia
}

Corresponding authors: A Bekker (adrie@sun.ac.za), L de Waard (ldewaard@sun.ac.za)

\begin{abstract}
Background. The impact of SARS-CoV-2 infection in pregnant women living with HIV (PLHIV) has not been described previously. Objectives. To describe the clinical presentation and outcomes of a cohort of women with high-risk pregnancies with confirmed COVID19 to determine whether risk factors for disease severity and adverse outcomes of COVID-19 differed in pregnant women without HIV compared with PLHIV.

Methods. We prospectively enrolled pregnant women with COVID-19 attending the high-risk obstetric service at Tygerberg Hospital, Cape Town, South Africa, from 1 May to 31 July 2020, with follow-up until 31 October 2020. Women were considered high risk if they required specialist care for maternal, neonatal and/or anaesthetic conditions. Common maternal or obstetric conditions included hypertensive disorders, morbid obesity (body mass index $(B M I) \geq 40 \mathrm{~kg} / \mathrm{m}^{2}$ ) and diabetes. Information on demographics, clinical features, and maternal and neonatal outcomes was collected and compared for PLHIV v. pregnant women without HIV.

Results. One hundred women (72 without HIV and 28 PLHIV) with high-risk pregnancies had laboratory-confirmed COVID-19. Among the 28 PLHIV, the median (interquartile range) CD4 count was 441 (317 - 603) cells/ $\mu \mathrm{L}$, and 19/26 (73\%) were virologically suppressed. COVID-19 was diagnosed predominantly in the third trimester (81\%). Obesity (BMI $\geq 30$ in $n=61 / 81 ; 75 \%$ ) and hypertensive disorders were frequent comorbidities. Of the 100 women, $40 \%$ developed severe or critical COVID-19, 15\% required intensive care unit admission and $6 \%$ needed invasive ventilation. Eight women died, 1 from advanced HIV disease complicated by bacteraemia and urosepsis. The crude maternal mortality rate was substantially higher in women with COVID-19 compared with all other deliveries at our institution during this period ( $8 / 91$ (9\%) v. $7 / 4058(0.2 \%)$; $p<0.001)$. Neonatal outcomes were favourable. No significant differences in COVID-19 risk factors, disease severity, and maternal/neonatal outcome were noted for PLHIV v. those without HIV.

Conclusions. In this cohort of high-risk pregnant women, the impact of COVID-19 was severe, significantly increasing maternal mortality risk compared with baseline rates. Virally suppressed HIV infection was not associated with worse COVID-19 outcomes in pregnancy.
\end{abstract}

S Afr Med J 2021;111(12):1174-1180. https://doi.org/10.7196/SAMJ.2021.v111i12.15683

South Africa (SA) has the highest number of confirmed positive SARS-CoV-2 infections on the African continent, with 1491807 laboratory-confirmed COVID-19 cases and 47899 COVID-related deaths recorded from the first case on 5 March 2020 until 13 February 2021. ${ }^{[1]}$ Population cohort analysis data from Western Cape Province, SA, demonstrated a doubling of COVID-19 mortality risk in persons living with $\mathrm{HIV}^{[2]}$ Although more data confirming the interaction between COVID-19 and HIV are emerging globally, ${ }^{[3,4]}$ there are limited data available for COVID-19 in pregnant women living with HIV (PLHIV). ${ }^{[5]}$

Infection rates for COVID-19 are higher in pregnant women than in adults of similar age in the general population. ${ }^{[6]}$ Risk factors for severe COVID-19 are well described and are similar for pregnant women, including pre-existing comorbidities, advanced maternal age and obesity. ${ }^{[7-9]}$ Immunological changes associated with pregnancy may also predispose pregnant women to severe viral infections, as observed during the 2009 influenza A (H1N1) pandemic. ${ }^{[10,11]}$ There is mounting evidence that pregnant women with COVID-19 have higher rates of intensive care unit (ICU) admission, invasive ventilation and mortality compared with nonpregnant individuals. ${ }^{[12]}$ Whether concomitant HIV infection in pregnancy affects SARS-CoV-2 infection risk, disease severity and COVID-19 outcome is currently unknown.

\section{Objectives}

In this prospective observational cohort study, we describe women with high-risk pregnancies and confirmed COVID-19 presenting to a large referral hospital in Cape Town, SA. Our objectives were: (i) to describe the clinical presentation and outcomes of women with high-risk pregnancies diagnosed with COVID-19; (ii) to determine whether risk factors for severe disease and adverse outcomes of COVID-19, including the need for respiratory support, ICU admission and death, differed in pregnant women without HIV compared with PLHIV; and (iii) to compare the number of maternal 
deaths, rates of multiple births, caesarean sections and stillbirths, and the number of low-birthweight (LBW) infants for COVID-19 pregnancies compared with all deliveries at our hospital during the study period.

\section{Methods \\ Study design}

We conducted an observational cohort study of pregnant women with COVID-19 who were attending the high-risk obstetric service at Tygerberg Hospital (TBH), Cape Town, SA. We included women who presented to the service between 1 May and 31 July 2020. All pregnant women with laboratory-confirmed positive SARS$\mathrm{CoV}-2$ reverse transcriptase-polymerase chain reaction (RT-PCR) results during these 3 months were prospectively and consecutively included. Women were followed up until 31 October 2020 to allow them all to deliver.

\section{Participants}

Pregnant women attending the high-risk obstetric care service were screened for symptoms and/or signs of COVID-19, or contact exposure. Only women who screened positive for symptoms had nasopharyngeal swab tests submitted for SARS-CoV-2 RT-PCR, as testing capacity was limited. We also included women whose symptoms and/or positive SARS-CoV-2 test result occurred within 7 days of delivery, as it was likely that they had contracted SARSCoV-2 infection during pregnancy. All women who had symptoms and/or a positive test $>7$ days post partum were excluded.

\section{Study setting}

TBH is the largest public sector referral hospital in Cape Town. The obstetric service delivers $>8000$ women a year and only manages high-risk pregnancies. The caesarean section rate (48\%) and LBW rate (39\%) at TBH are both high. ${ }^{[13]}$ Common high-risk maternal or obstetric conditions include hypertensive disorders, morbid obesity (body mass index (BMI) $\geq 40 \mathrm{~kg} / \mathrm{m}^{2}$ ) and diabetes. ${ }^{[14]}$ According to SA referral guidelines, all women in the referral hospital's drainage area with a BMI $\geq 40 \mathrm{~kg} / \mathrm{m}^{2}$ have to be referred to the referral hospital and delivered in the hospital. HIV is not considered a high-risk factor in our setting. Testing for HIV is offered to all pregnant women at their first antenatal visit and is repeated at 32 weeks' gestation and at delivery, according to national guidelines. ${ }^{[15]}$ With expanded access to diagnosis of and treatment for HIV, increasing numbers of women are initiated on combination antiretroviral therapy (cART) before falling pregnant. ${ }^{[16]}$ Universal cART for all PLHIV was introduced in 2015. ${ }^{[16]}$ Approximately $20 \%$ of all women who deliver at TBH are PLHIV, with an intrauterine HIV transmission rate of $0.82 \% .{ }^{[17]}$

In preparation for the COVID-19 pandemic, a dedicated obstetric unit (separate ward, theatres and staff) was established for the care of pregnant women with suspected and confirmed COVID-19. This unit was staffed by senior obstetric trainees, nursing and midwifery teams who were supported by critical care consultants, obstetricians, and anaesthetic and neonatology staff. Where possible, healthy neonates were kept with their mothers to establish breastfeeding. In line with national protocols, SARS-CoV-2 RT-PCR testing was not performed for healthy neonates born to mothers with COVID-19. If a neonate required admission to any neonatal ward, SARS-CoV-2 testing was performed.

\section{Data collection and classification}

The obstetric trainee team and research midwife prospectively collected routine clinical data and laboratory outcomes on all pregnant women with confirmed COVID-19. Data included demographics, HIV information, COVID-19 symptoms, pregnancy complications, and birth and neonatal outcomes. Data on the number of deliveries, the route of delivery and maternal/neonatal outcome are routinely captured on an electronic birth register at TBH. Data for the patients with COVID-19 were collected using a secure online Research Electronic Data Capture (REDCap) data registry hosted by Stellenbosch University. ${ }^{[18,19]}$ Ethical approval was obtained from the Stellenbosch University Health Research Ethics Committee (ref. no. N20/04/002_COVID-19).

BMI was corrected for the trimester when first weight measurements were taken, to adjust for expected weight gain during pregnancy as per provincial policy. If measured in the second trimester, $4 \mathrm{~kg}$ was deducted, and in the third trimester, $8 \mathrm{~kg}$ was deducted. A miscarriage was defined as the accidental loss of a fetus before 24 weeks' gestation. ${ }^{[20]}$ COVID-19 severity (mild/moderate v. severe/critical) was classified using the National Institutes of Health criteria. ${ }^{[21]}$ Mild or moderate illness was defined as symptomatic women not needing oxygen supplementation, while women with respiratory symptoms requiring oxygen supplementation were defined as having severe illness. Critical illness included respiratory failure, septic shock, and/ or multiorgan dysfunction.

\section{Statistical analysis}

Descriptive analysis was conducted reporting counts and proportions. Non-parametric data were described using medians and interquartile ranges (IQRs). Pregnant women with COVID-19 were analysed by HIV status. Mild or moderate COVID-19 was compared with severe or critical COVID-19. Student's $t$-test or the Mann-Whitney $U$-test was used for comparing continuous data, and the $\chi^{2}$ test or Fisher's exact test was used for comparing categorical data. A $p$-value $<0.05$ was considered statistically significant.

\section{Results \\ SARS-CoV-2 laboratory testing of high-risk pregnant women}

SARS-CoV-2 RT-PCR testing was performed in 275 women attending the high-risk obstetric service between 1 May and 31 July 2020. COVID-19 was confirmed in 103/275 women (37\%), of whom 3 were excluded because their COVID-19 symptoms started $>7$ days post partum. The final cohort of 100 pregnant women was followed up until 31 October 2020 to allow all of them to deliver.

\section{Pre-existing medical and obstetric conditions in women with COVID-19}

Seventy-two of the 100 pregnant women with COVID-19 were HIV-uninfected and 28 were PLHIV (Table 1). Twenty-seven of 28 PLHIV (96\%) were receiving cART at the time of delivery. CD4 counts were available for 21/28 women (75\%) (median (IQR) 441 (317 - 603) cells $/ \mu \mathrm{L})$, and 19/26 (73\%) were virologically suppressed (HIV viral load $<50$ copies $/ \mathrm{mL}$ ). For the 7 PLHIV with a detectable HIV viral load, the median (IQR) viral load was 361 (104 - 461) copies $/ \mathrm{mL}$. The viral load was not available for 2 women. PLHIV were more likely to be older and multiparous compared with women without HIV. Obesity was a frequent comorbidity (weights available for $81 / 100$ ), with $25 / 81$ (31\%) obese and $36 / 81$ (44\%) morbidly obese women; no difference was observed between PLHIV and women without HIV. Pre-existing chronic hypertension and diabetes mellitus were present in 22/100 and 6/100 women, respectively, and $9 / 100$ women had a previous or current diagnosis of tuberculosis. 
SAMJ RESEARGH

Table 1. Demographics, COVID-19 and pregnancy outcomes by HIV status

\begin{tabular}{|c|c|c|c|c|}
\hline & All women $(N=100)$ & Without HIV $(N=72)$ & With HIV $(N=28)$ & $p$-value \\
\hline \multicolumn{5}{|l|}{ Demographics } \\
\hline Age (years), median (IQR) & $31(27-37)$ & $31(27-36)$ & $34(28-39)$ & 0.082 \\
\hline \multicolumn{5}{|l|}{$\operatorname{BMI}\left(\mathrm{kg} / \mathrm{m}^{2}\right),{ }^{*} n(\%)$} \\
\hline$<25$ (normal weight) & $8 / 81(10)$ & $6 / 59(10)$ & $2 / 22(9)$ & 0.603 \\
\hline$\geq 25-<30$ (overweight) & $12 / 81(15)$ & $9 / 59(15)$ & $3 / 22(14)$ & 0.554 \\
\hline$\geq 30-<40$ (obese) & $25 / 81(31)$ & $16 / 59(27)$ & $9 / 22(41)$ & 0.304 \\
\hline$\geq 40$ (morbidly obese) & $36 / 81(44)$ & $28 / 59(48)$ & $8 / 22(36)$ & 0.334 \\
\hline Multiparous, $n(\%)$ & $78(78)$ & $51(71)$ & $27(96)$ & 0.006 \\
\hline Twin pregnancy, $n(\%)$ & $5(5)$ & $5(7)$ & $0(0)$ & 0.186 \\
\hline Chronic hypertension, $n$ (\%) & $22(22)$ & $19(26)$ & $3(11)$ & 0.089 \\
\hline Gestational hypertension, $n(\%)$ & $18(18)$ & $13(18)$ & $5(18)$ & 0.981 \\
\hline Pre-eclampsia, $n(\%)$ & $24(24)$ & $18(25)$ & $6(21)$ & 0.733 \\
\hline Diabetes mellitus, $n(\%)$ & $6(6)$ & $4(6)$ & $2(7)$ & $\mathrm{n} / \mathrm{a}$ \\
\hline Gestational diabetes, $n(\%)$ & $14(14)$ & $12(17)$ & $2(7)$ & 0.183 \\
\hline Asthma, $n(\%)$ & $4(4)$ & $4(6)$ & $(0)$ & $\mathrm{n} / \mathrm{a}$ \\
\hline Tuberculosis (current and previous), $n$ (\%) & $9(9)$ & $5(7)$ & $4(14)$ & $\mathrm{n} / \mathrm{a}$ \\
\hline Anaemia, ${ }^{\dagger} n(\%)$ & $28(28)$ & $17(24)$ & $11(39)$ & 0.117 \\
\hline \multicolumn{5}{|l|}{ COVID-19 } \\
\hline \multicolumn{5}{|l|}{ Timing of infection, $n(\%)$} \\
\hline 1st trimester & $2(2)$ & $1(1)$ & $1(4)$ & $\mathrm{n} / \mathrm{a}$ \\
\hline 2nd trimester & $17(17)$ & $13(18)$ & $4(14)$ & 0.451 \\
\hline 3rd trimester & $81(81)$ & $58(81)$ & $23(82)$ & 0.856 \\
\hline Delivery within 2 weeks of diagnosis, $n(\%)$ & $50(50)$ & $33(46)$ & $17(61)$ & 0.181 \\
\hline \multicolumn{5}{|l|}{ Symptoms } \\
\hline Cough, $n(\%)$ & $77(77)$ & $56(78)$ & $21(75)$ & 0.767 \\
\hline Dyspnoea, $n(\%)$ & $49(49)$ & $35(49)$ & $14(50)$ & 0.901 \\
\hline Fever, $n(\%)$ & $36(36)$ & $26(36)$ & $10(36)$ & 0.970 \\
\hline Duration of symptoms (days), median (IQR) & $3(2-5)$ & $3(2-4)$ & $3(1-6)$ & $\mathrm{n} / \mathrm{a}$ \\
\hline \multicolumn{5}{|l|}{ Disease severity, $n(\%)$} \\
\hline Mild & $60(60)$ & $43(60)$ & $17(61)$ & 0.928 \\
\hline Severe & $29(29)$ & $20(28)$ & $9(32)$ & 0.666 \\
\hline Critical & $11(11)$ & $9(12)$ & $2(7)$ & $\mathrm{n} / \mathrm{a}$ \\
\hline \multicolumn{5}{|l|}{ Maximum respiratory support, $n(\%)$} \\
\hline Nasal prong oxygen & $16 / 40(40)$ & $12 / 29(42)$ & $4 / 11(36)$ & 0.533 \\
\hline Face mask oxygen/non-rebreather mask & $13 / 40(33)$ & $9 / 29(31)$ & $4 / 11(36)$ & 0.514 \\
\hline High-flow oxygen/nCPAP & $5 / 40(12)$ & $3 / 29(10)$ & 2/11 (19) & 0.422 \\
\hline Invasive ventilation & $6 / 40(15)$ & $5 / 29(17)$ & $1 / 11(9)$ & 0.464 \\
\hline \multicolumn{5}{|l|}{ Treatments, $n(\%)$} \\
\hline Thromboprophylaxis & $59(59)$ & $39(54)$ & $20(71)$ & 0.115 \\
\hline Dexamethasone $e^{*}$ & $13(13)$ & $7(10)$ & $6(22)$ & 0.111 \\
\hline Hydrocortisone & $3(3)$ & $3(4)$ & 0 & $\mathrm{n} / \mathrm{a}$ \\
\hline Methylprednisolone & $1(1)$ & $1(1)$ & 0 & $\mathrm{n} / \mathrm{a}$ \\
\hline Antibiotics ${ }^{\S}$ & $55(55)$ & $38(53)$ & $17(61)$ & 0.474 \\
\hline \multicolumn{5}{|l|}{ Complications } \\
\hline Thromboembolism, $n(\%)$ & $4(4)$ & $2(3)$ & $2(2)$ & $\mathrm{n} / \mathrm{a}$ \\
\hline Acute kidney injury, $n$ (\%) & $3(3)$ & $2(3)$ & $1(4)$ & $\mathrm{n} / \mathrm{a}$ \\
\hline ICU admission, $n(\%)$ & $15(15)$ & $9(13)$ & $6(21)$ & 0.206 \\
\hline ICU stay (days), median (IQR) & $4(3-10)$ & $5(4-10)$ & $3(1-6)$ & 0.271 \\
\hline \multicolumn{5}{|l|}{ Pregnancy outcomes, $n(\%)$} \\
\hline Caesarean section & $49(49)$ & $30(42)$ & $19(68)$ & 0.019 \\
\hline Vaginal delivery with live birth & $37(37)$ & $32(44)$ & $5(18)$ & 0.013 \\
\hline Stillbirth & $5(5)$ & $3(4)$ & $2(7)$ & $\mathrm{n} / \mathrm{a}$ \\
\hline Medical termination of pregnancy & $1(1)$ & $1(4)$ & 0 & $\mathrm{n} / \mathrm{a}$ \\
\hline Miscarriage & $4(4)$ & $3(4)$ & $1(4)$ & $\mathrm{n} / \mathrm{a}$ \\
\hline Mother died with fetus in utero & $2(2)$ & $2(3)$ & 0 & $\mathrm{n} / \mathrm{a}$ \\
\hline Unknown & $2(2)$ & $2(3)$ & 0 & $\mathrm{n} / \mathrm{a}$ \\
\hline Spontaneous preterm labour $<37$ weeks & $4(4)$ & $3(4)$ & $1(4)$ & $\mathrm{n} / \mathrm{a}$ \\
\hline Placental abruption & $2(2)$ & $2(3)$ & 0 & $\mathrm{n} / \mathrm{a}$ \\
\hline Maternal death & $8(8)$ & $6(8)$ & $2(7)$ & $\mathrm{n} / \mathrm{a}$ \\
\hline 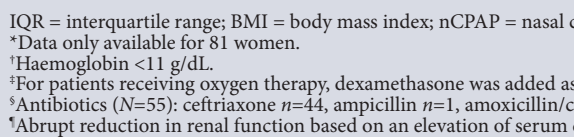 & $\begin{array}{l}\text { re from } 17 \text { June } 2020 . \\
=6 \text {, azithromycin } n=1 \text {, cer } \\
\text { fold from baseline. }\end{array}$ & ensive care unit; $\mathrm{n} / \mathrm{a}=$ not app. & & \\
\hline
\end{tabular}




\section{COVID-19 in 100 women with high-risk pregnancies}

Fourteen women were managed as outpatients and 86 required hospital admission. Common symptoms included cough (77\%), dyspnoea (49\%) and fever (36\%). Of the 86 admissions, 46 (53\%) were for COVID-19-related illness, 23 (27\%) for delivery, and 17 (20\%) for other obstetric indications. The median hospital stay was 4 days (range 1 - 25). COVID-19 was diagnosed mainly in the third trimester (81\%), and half of all women delivered within 2 weeks of infection onset.

Sixty women had mild/moderate COVID-19, 29 had severe disease and 11 had critical disease. Of the 11 women with critical disease, 6 were ventilated for respiratory failure and 1 collapsed and died in the ward prior to ICU admission. The remaining 4 did not require ventilation but presented with multiorgan dysfunction in addition to COVID-19 pneumonia: 1 with cardiomyopathy needing inotropic support, 1 with glucose instability requiring an insulin infusion, 1 with delirium, and 1 with bacteraemia and urosepsis.

Of the $30 / 40$ women in the severe/critical disease categories whose weight was documented, all were either overweight $(3 / 30 ; 10 \%)$, obese $(9 / 30 ; 30 \%)$ or morbidly obese $(18 / 30 ; 60 \%)$. No difference in proportions was observed between PLHIV with mild/moderate disease compared with PLHIV with severe/critical disease ( $n=17 / 60$ $(28 \%)$ v. $11 / 40(28 \%) ; p=0.928)$. Dyspnoea was more common in the severe or critical disease group compared with mild or moderate disease (33/40 (83\%) v. 16/60 (27\%); $p=0.001)$

Women with severe/critical disease were also more likely to need other supportive treatment including anticoagulation (32/40;80\%), dexamethasone $(13 / 40 ; 33 \%)$ and broad-spectrum antibiotics $(29 / 40$; $73 \%)$. Fifteen women required admission to the ICU or the maternity critical care unit, 12 primarily for respiratory support and 3 for nonCOVID-19-related conditions (diabetic ketoacidosis, a caesarean hysterectomy, and severe pre-eclampsia).

No differences between PLHIV and women without HIV were found with regard to the timing of infection, type and duration of symptoms, disease severity, need for respiratory support, other medical treatment, or complications. Pregnancy outcomes for the 100 women (5 twin pregnancies) included 91 live births, 5 stillbirths, 4 miscarriages, 2 women who died with the fetus in utero and 1 medical termination of pregnancy. The 2 women who died with the fetus in utero died from complications of COVID-19. The medical termination was for severe preterm pre-eclampsia. There were 3 first-trimester miscarriages, and 1 at 19 weeks due to diabetic ketoacidosis. One baby was stillborn to a mother who defaulted her cART, 2 stillbirths were associated with severe pre-eclampsia, 1 was due to a placental abruption without associated pre-eclampsia, and the 5th was in a woman who had severe hypoxia related to COVID-19. Birth outcomes were unknown for 2 women who were lost to follow-up. No differences were observed for pregnancy outcomes in terms of HIV status, except for a higher caesarean section rate in older, multiparous PLHIV, where 9/19 (47\%) had a history of two previous caesarean sections.

\section{Maternal mortality}

Eight women in this cohort died, of whom 2 were PLHIV. One woman died from advanced HIV and 7 from complications related to COVID-19 (Table 2). The woman with advanced HIV had a CD4 count of 14 cells $/ \mu \mathrm{L}$ and had defaulted her cART in 2018. She had not received any antenatal care and delivered a macerated fetus weighing 1131 g. She was diagnosed with Escherichia coli septicaemia, cultured in both blood and urine samples, and died 8 days later from urosepsis and acute renal failure. Her GeneXpert test for tuberculosis was also positive. The other PLHIV had a suppressed viral load and no clinical indications of advanced HIV disease.
Weight and height measurements were available for 6 of the 7 women whose deaths were directly related to COVID-19. One woman was overweight, and the others were all obese. Five women had chronic hypertension, and 2 of these women developed severe pre-eclampsia. Two women had pregnancies complicated by type 2 diabetes mellitus. Two women died with the fetus in situ. One woman had a caesarean section for severe pre-eclampsia and developed COVID-19 symptoms post partum. Four women needed a caesarean section delivery to improve respiratory function. One neonate was delivered close to term and 2 were delivered preterm. One woman who was delivered to improve her respiratory function had a neonatal death related to intrauterine hypoxia.

\section{Neonatal outcomes}

Among the 91 liveborn neonates (66 in women without HIV and 25 in PLHIV), the median (IQR) gestational age at delivery was 38 (36 $39)$ weeks (Table 3 ). Twenty-seven infants $(30 \%)$ were preterm and 25 (28\%) were LBW. Of the 91 liveborn neonates, 76 (84\%) remained with their mother and $15(16 \%)$ were admitted to a neonatal ward; the median (IQR) gestational age of admitted infants was 34 (26 38) weeks. Reasons for admission included diagnoses of respiratory distress syndrome in 9 , transient tachypnoea of the newborn in 2 , congenital pneumonia in 2, jaundice, hypoglycaemia, and 1 neonate with an imperforate anus who required surgery. Of these 15 admitted neonates, 14 required respiratory support, including invasive ventilation in 1 , nasal continuous positive airway pressure ventilation in 12 and nasal cannula oxygen in 1 . The neonatal stay ranged from 5 to 30 days. A SARS-CoV-2 test was negative in 13/15 admitted neonates within 72 hours after birth (invalid in 1 and not done in another). No differences in neonatal birthweight or outcome were observed between neonates born to women without HIV v. PLHIV. The neonatal outcomes of the mothers who died of COVID-19 were poor. There were 4 intrauterine fetal deaths and 1 early neonatal loss in a neonate who had no respiratory effort at birth. There were 2 preterm deliveries, one at 32 weeks' gestation with a $1945 \mathrm{~g}$ neonate and another at 26 weeks with a neonate weighing $750 \mathrm{~g}$ (Table 2). The outcome for the 91 liveborn neonates was excellent except for the neonate described above whose mother also died.

Key obstetric indicators for pregnancies at TBH affected and unaffected by COVID-19 (1 May - 31 October 2020) A total of 4149 women with high-risk pregnancies were delivered at TBH during this time frame, 91 with COVID-19 (9 from the cohort delivered at other institutions) and 4058 not included in the study cohort. No differences were observed in the rates of multiple pregnancy, caesarean section, stillbirth and live LBW infants, but the crude maternal mortality rate was substantially increased in women with COVID-19 compared with women without suspected COVID$19(n=8 / 91(8.8 \%)$ v. $n=7 / 4058$ (0.2\%); $p<0.001)$ (Fig. 1).

\section{Discussion}

Our observational study is the first to assess the impact of laboratoryconfirmed COVID-19 in a cohort of high-risk pregnant women from sub-Saharan Africa, including women living with HIV. Of the 28 PLHIV (a quarter of the total cohort), the majority were receiving cART and were virally suppressed. In this group of highrisk pregnancies with well-controlled HIV disease, we found no differences in COVID-19 risk factors, disease severity or outcomes for both mothers and their neonates, compared with COVID-19 pregnant women without HIV infection. 


\begin{tabular}{|c|c|c|c|c|c|c|c|c|}
\hline $\begin{array}{l}\text { Age } \\
\text { (years) }\end{array}$ & Gravidity & Parity & $\begin{array}{l}\text { BMI } \\
\left(\mathrm{kg} / \mathrm{m}^{2}\right)\end{array}$ & Other risk factors & Delivery & Neonatal outcome & Maternal outcome & Death \\
\hline 29 & 2 & 1 & 25 & $\begin{array}{l}\text { Advanced HIV } \\
\text { Defaulted cART } \\
\text { Chronic leg ulcer } \\
\text { Active TB } \\
\text { Urosepsis } \\
\text { No antenatal care }\end{array}$ & $\begin{array}{l}\text { Spontaneous } \\
\text { vaginal delivery }\end{array}$ & $\begin{array}{l}\text { Macerated stillborn, } \\
1131 \mathrm{~g}\end{array}$ & $\begin{array}{l}\text { Severe sepsis } \\
\text { Renal failure }\end{array}$ & $\begin{array}{l}\text { Day } 7 \\
\text { postpartum }\end{array}$ \\
\hline 28 & 2 & 1 & 25 & $\begin{array}{l}\text { Chronic } \\
\text { hypertension } \\
\text { Superimposed pre- } \\
\text { eclampsia }\end{array}$ & $\begin{array}{l}\text { Emergency CS } \\
\text { at } 26 \text { weeks for } \\
\text { severe features } \\
\text { of superimposed } \\
\text { pre-eclampsia }\end{array}$ & $\begin{array}{l}\text { Baby alive, } 750 \mathrm{~g} \\
\text { Admitted to NICU } \\
\text { No COVID } \\
\text { symptoms }\end{array}$ & $\begin{array}{l}\text { COVID symptoms } \\
2 \text { days postpartum } \\
\text { Intubated and } \\
\text { ventilated } \\
\text { Multiorgan failure }\end{array}$ & $\begin{array}{l}\text { Day } 5 \\
\text { postpartum }\end{array}$ \\
\hline 37 & 2 & 1 & 48 & $\begin{array}{l}\text { Chronic } \\
\text { hypertension } \\
\text { Superimposed pre- } \\
\text { eclampsia } \\
\text { Type } 2 \text { DM } \\
\text { Anaemia }\end{array}$ & $\begin{array}{l}\text { CS at } 30 \text { weeks } \\
\text { for deteriorating } \\
\text { maternal } \\
\text { condition related } \\
\text { to COVID-19 }\end{array}$ & $\begin{array}{l}\text { Neonatal death, } \\
1500 \mathrm{~g} \\
\text { No respiratory effort } \\
\text { 5-minute Apgar } \\
\text { Failed resuscitation }\end{array}$ & $\begin{array}{l}\text { Intubated and } \\
\text { ventilated } \\
\text { Acute renal injury } \\
\text { Repeat laparotomy }\end{array}$ & $\begin{array}{l}\text { Day } 7 \\
\text { postpartum }\end{array}$ \\
\hline 35 & 5 & 4 & 39 & $\begin{array}{l}\text { Chronic } \\
\text { hypertension } \\
\text { Asthma }\end{array}$ & $\begin{array}{l}\text { CS at } 36 \text { weeks } \\
\text { for deteriorating } \\
\text { maternal } \\
\text { condition related } \\
\text { to COVID-19 }\end{array}$ & $\begin{array}{l}\text { Intrauterine death, } \\
2685 \mathrm{~g}\end{array}$ & $\begin{array}{l}\text { Intubated and } \\
\text { ventilated } \\
\text { Multiorgan failure }\end{array}$ & $\begin{array}{l}\text { Day } 1 \\
\text { postpartum }\end{array}$ \\
\hline 38 & 6 & 5 & 40 & $\begin{array}{l}\text { Chronic } \\
\text { hypertension }\end{array}$ & Undelivered & $\begin{array}{l}\text { Intrauterine death at } \\
27 \text { weeks' gestation }\end{array}$ & $\begin{array}{l}\text { Intubated and } \\
\text { ventilated }\end{array}$ & $\begin{array}{l}\text { Day } 4 \text { after } \\
\text { admission }\end{array}$ \\
\hline 33 & 3 & 1 & 30 & $\begin{array}{l}\text { Chronic } \\
\text { hypertension } \\
\text { Anaemia } \\
\text { PLHIV }\end{array}$ & $\begin{array}{l}\text { CS at } 37 \text { weeks } \\
\text { for deteriorating } \\
\text { maternal } \\
\text { condition related } \\
\text { to COVID-19 }\end{array}$ & $\begin{array}{l}\text { Baby alive, } 2350 \mathrm{~g} \\
\text { No COVID } \\
\text { symptoms }\end{array}$ & $\begin{array}{l}\text { Repeat laparotomy } \\
\text { day } 2 \text { postpartum } \\
\text { Intubated and } \\
\text { ventilated on day } 7 \\
\text { 2nd repeat } \\
\text { laparotomy day } 9\end{array}$ & $\begin{array}{l}\text { Day } 9 \\
\text { postpartum }\end{array}$ \\
\hline 40 & 5 & 2 & 55 & $\begin{array}{l}\text { Gestational } \\
\text { hypertension } \\
\text { Type } 2 \text { DM } \\
\text { Anaemia }\end{array}$ & Undelivered & $\begin{array}{l}\text { Intrauterine death at } \\
26 \text { weeks' gestation }\end{array}$ & $\begin{array}{l}\text { Cardiac arrest } \\
\text { Possible } \\
\text { thrombotic event }\end{array}$ & $\begin{array}{l}\text { Day } 4 \text { after } \\
\text { admission }\end{array}$ \\
\hline 28 & 3 & 2 & Unknown & None & $\begin{array}{l}\text { CS at } 32 \text { weeks } \\
\text { for deteriorating } \\
\text { maternal } \\
\text { condition related } \\
\text { to COVID-19 }\end{array}$ & $\begin{array}{l}\text { Baby alive, } 1945 \mathrm{~g} \\
\text { No COVID } \\
\text { symptoms }\end{array}$ & $\begin{array}{l}\text { Intubated and } \\
\text { ventilated } \\
\text { Severe hypoxia }\end{array}$ & $\begin{array}{l}\text { Day } 16 \\
\text { postpartum }\end{array}$ \\
\hline
\end{tabular}

Table 3. Demographics and outcome of live births to women with COVID-19

\begin{tabular}{|c|c|c|c|c|}
\hline Neonatal outcomes & Live births $(N=91)$ & Not exposed to HIV $(N=66)$ & Exposed to HIV $(N=25)$ & $p$-value \\
\hline Gestation at delivery (weeks), median (IQR) & $38(36-39)$ & $38(36-39)$ & $39(38-39)$ & 0.123 \\
\hline Delivered before 37 weeks, $n$ (\%) & $27(30)$ & $21(32)$ & $6(24)$ & 0.466 \\
\hline Birth weight (g), median (IQR) & $3085(2350-3520)$ & $3010(2380-3475)$ & $3300(2350-3545)$ & 0.475 \\
\hline Low birthweight (<2 $500 \mathrm{~g}), n$ (\%) & $25(28)$ & $18(27)$ & $7(28)$ & 0.945 \\
\hline Male, $n(\%)^{*}$ & $44 / 86(51)$ & $29 / 61(48)$ & $15 / 25(60)$ & 0.058 \\
\hline Neonatal ward admission, $n(\%)$ & $15(16)$ & $11(17)$ & $4(16)$ & 0.606 \\
\hline \multicolumn{5}{|l|}{ Infant feeding, $n(\%)$} \\
\hline Exclusive breastfeeding & $48(53)$ & $33(50)$ & $15(60)$ & 0.394 \\
\hline Exclusive formula feeding & $8(9)$ & $4(6)$ & $4(16)$ & $\mathrm{n} / \mathrm{a}$ \\
\hline Mixed feeding & $4(4)$ & $4(6)$ & 0 & $\mathrm{n} / \mathrm{a}$ \\
\hline Unknown & $31(34)$ & $25(38)$ & $6(24)$ & 0.212 \\
\hline Neonatal death & $1(1)$ & $1(2)$ & 0 & $\mathrm{n} / \mathrm{a}$ \\
\hline
\end{tabular}




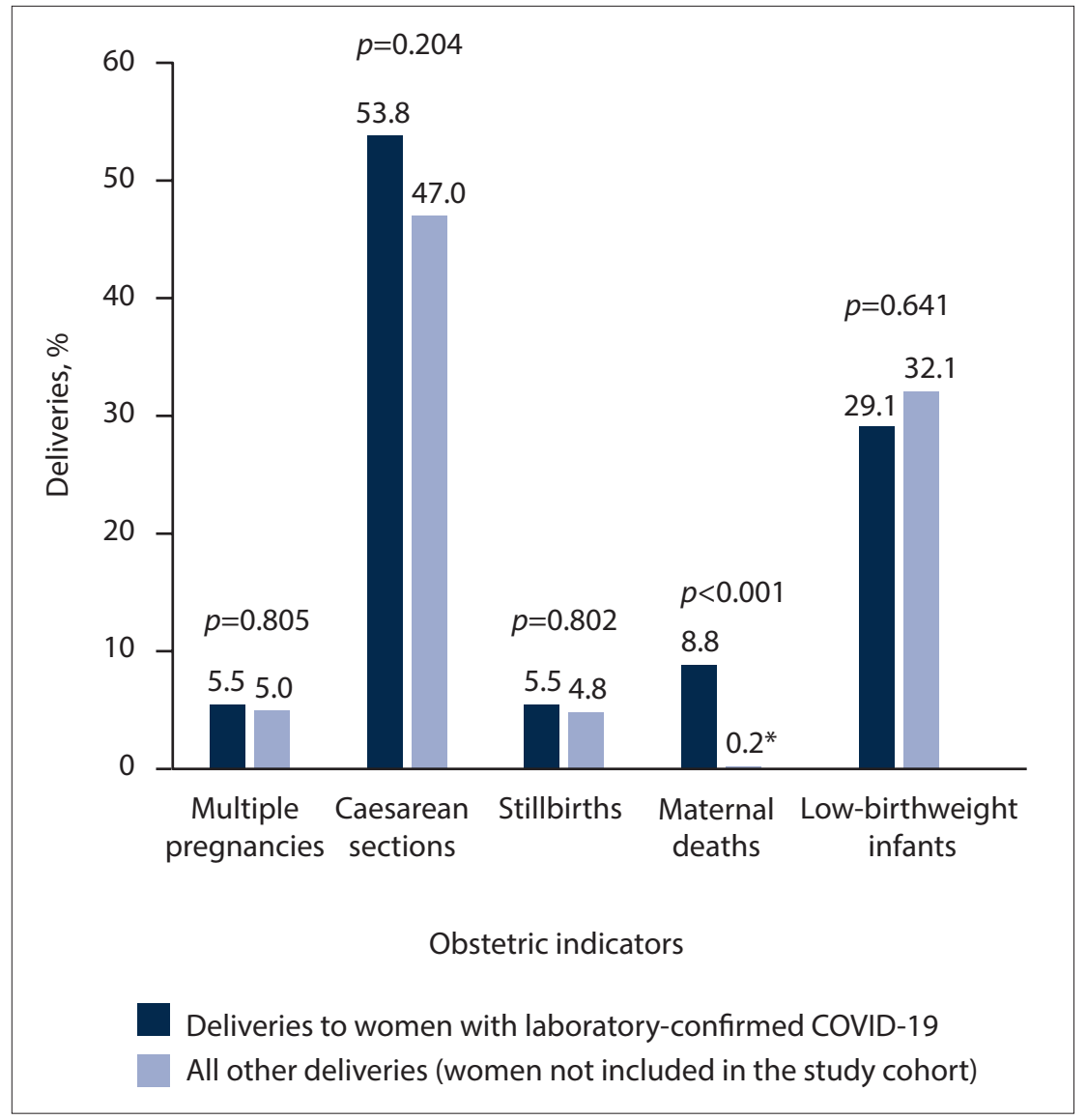

Fig. 1. Key obstetric indicators for women with COVID-19 v. all other women pregnant delivering at Tygerberg Hospital but not included in the study cohort, 1 May - 31 October 2020. ( ${ }^{*}$ Two pregnant women who died of COVID-19 did not meet the inclusion criteria for this study: one was $>7$ days post partum, and the other, who was 8 weeks pregnant, was never managed by the obstetric team. These women were added to the numerator for calculation of maternal deaths of women not included in the study cohort.)

Of the cohort of 100 pregnant women with COVID-19, most were overweight or obese and many had underlying risk factors for severe COVID-19, including hypertension and diabetes mellitus. Risk factors for severe and critical disease in pregnant women with COVID-19 are similar to those in nonpregnant populations. ${ }^{[22]}$ Severe COVID-19 in pregnancy has been associated with high BMI (odds ratio 2.38; 95\% CI 1.67 - 3.39; three studies, 877 women). ${ }^{[7]}$ In our study, $90 \%$ of the 40 women who developed severe/critical COVID-19 were either obese or morbidly obese. The high proportion of our cohort that developed severe/critical COVID-19 exceeds previous reports, ${ }^{[23]}$ but the finding is not surprising, because our institution serves as a referral centre for severely ill patients and manages high-risk pregnancies, and only symptomatic women were tested.

Accumulating evidence demonstrates that pregnant women with COVID-19 are more likely to need admission to an ICU and require invasive ventilation than non-
Preterm birth rates of between $12.6 \%$ and $17 \%$ have been documented in women with COVID-19. ${ }^{[7,24]}$ The overall preterm birth rate in our cohort was high (30\%), but it is similar to that for our high-risk obstetric unit. No difference was observed between rates of LBW in women with COVID-19 v. women without. In contrast to many other studies, where a quarter of all neonates born to mothers with COVID-19 were admitted to a neonatal ward, ${ }^{[7]}$ the majority of our neonates $(84 \%)$ remained in the care of their mothers. Only $16 \%$ were admitted to the neonatal ward, mainly owing to complications of prematurity. No perinatal COVID-19 transmission was documented in the few neonates admitted to the neonatal ICU, in support of other literature showing that perinatal COVID-19 transmission is rare. ${ }^{[8]}$

\section{Study strengths and limitations}

To our knowledge, this is the first observational cohort from Africa to report on COVID19 in high-risk pregnant women including PLHIV. It adds important information to aid in the management of PLHIV with COVID19. SA has 7.7 million people living with HIV, with $\sim 4.7$ million on cART. ${ }^{[27]}$ Further studies are needed to fully assess the impact of COVID-19 on PLHIV. The impact on PLHIV who are newly diagnosed and not virally suppressed also needs further investigation. SA has reported many COVID-19 cases, owing to a high burden of disease and good laboratory access for testing. Unfortunately, the spread of the disease elsewhere in Africa has been less well characterised, with only a few small observational studies documenting the effect of COVID-19 on African pregnant women. ${ }^{[28]}$ Etti et al. ${ }^{[5]}$ plan to address some of these knowledge gaps by screening $>50000$ pregnant women from five subSaharan countries, which will provide more information on the burden of COVID-19 in pregnant women on the continent.

We acknowledge the following limitations of the study. TBH only manages highrisk pregnancies, and these results are not generalisable to all pregnant women. The high proportion of pregnant women with a BMI $\geq 40 \mathrm{~kg} / \mathrm{m}^{2}$ may have contributed to a higher proportion of severe COVID19. The numbers are relatively small in some subanalyses, and results should be interpreted with caution. Information regarding the date of HIV diagnosis, staging of HIV disease, and type and duration of cART was not available. As the majority of our PLHIV cohort were virally suppressed, we could only assess the impact of COVID19 on high-risk pregnancies with wellcontrolled HIV infection. 


\section{Conclusions}

In this cohort of high-risk pregnant women with COVID-19, the impact of the disease in pregnancy was severe; however, no clinical differences in outcome attributable to virally suppressed HIV infection were noted. We observed a high maternal mortality rate with poor outcomes for mother and fetus in women who developed critical COVID-19, compared with our institution's baseline nonCOVID-19-associated maternal mortality rate. Despite these pregnant women being very ill, all but one of the liveborn neonates survived to hospital discharge.

\section{Declaration. None.}

Acknowledgements. We thank all the staff at TBH who assisted with managing these patients and collecting the data.

Author contributions. LdW, EL, JT, AD, CAC and AB conceived the study. Data collection was performed by KE, TvdM, SEO, NdT, CP, NN, $\mathrm{MvN}, \mathrm{AM}, \mathrm{SS}$ and MHB. $\mathrm{AB}$ and $\mathrm{AD}$ analysed the data. $\mathrm{LdW}, \mathrm{AB}, \mathrm{AD}$ and $\mathrm{CAC}$ led the writing of the manuscript. All authors contributed to the written manuscript.

Funding. AD is supported by a National Institutes of Health Fogarty Emerging Global Leader Award (NIH K43 TW010682). Mercy Perinatal Foundation provided salary support to CAC and our research midwife SS. The Swedish Society of Medicine and the Märta Lundqvist Foundation also provided salary support for SS.

Conflicts of interest. None.

1. National Institute for Communicable Diseases. COVID-19 weekly epidemiology brief: South Africa: Week 6 2021. https://www.nicd.ac.za/wp-content/uploads/2021/02/COVID-19-WeeklyEpidemiology-Brief-week-6-2021.pdf (accessed 24 February 2021)

2. Boulle A, Davies M, Hussey H, et al. Risk factors for COVID-19 death in a population cohort study foulle A, Davies M, Hussey H, et al. Risk factors for COVID-19 death in a population cohort study
from the Western Cape Province, South Africa. Clin Infect Dis 2020;73(7):e2005-e2015. https://doi. $\mathrm{org} / 10.1093 / \mathrm{cid} / \mathrm{ciaa} 1198$

3. Etienne N, Karmochkine M, Slama L, et al. HIV infection and COVID-19: Risk factors for severe disease. AIDS 2020;34(12):1771-1774. https://doi.org/10.1097/QAD.0000000000002651

4. Parker A, Koegelenberg CFN, Moolla MS, et al. High HIV prevalence in an early cohort of hospital admissions with COVID-19 in Cape Town, South Africa. S Afr Med J 2020;110(10):982-987. https:// doi.org/10.7196/SAMJ.2020.v110i10.15067

5. Etti M, Sekikubo M, Nankabirwa V, et al. SARS-CoV-2 infection in pregnant women and their newborns. Ann Glob Health 2020;86(1):1-3. https://doi.org/10.5334/aogh.3072

6. Lokken EM, Taylor GG, Huebner EM, et al. Higher severe acute respiratory syndrome coronavirus 2 infection rate in pregnant patients. Am J Obstet Gynecol 2021;225(1):75.e1-75.e16. https://doi. org/10.1016/j.ajog.2021.02.011

7. Allotey J, Stallings $\mathrm{E}$, Bonet $\mathrm{M}$, et al. Clinical manifestations, risk factors, and maternal and perinatal outcomes of coronavirus disease 2019 in pregnancy: Living systematic review and meta-analysis. BMJ 2020;370:m3320. https://doi.org/10.1136/bmj.m3320

8. Knight M, Bunch K, Vousden N, et al. Characteristics and outcomes of pregnant women hospitalised with confirmed SARS-CoV-2 infection in the UK: National population based cohort study. BMJ 2020;369:m2107. https://doi.org/10.1136/bmj.m2107

9. Sentilhes L, de Marcillac F, Jouffrieau C, et al. Coronavirus disease 2019 in pregnancy was associated with maternal morbidity and preterm birth. Am J Obstet Gynecol 2020;223(6):914.e1-914.e15. https:// doi.org/10.1016/.j.ajog.2020.06.022
10. Mosby LG, Rasmussen SA, Jamieson DJ. 2009 pandemic influenza A (H1N1) in pregnancy: A systematic review of the literature. Am J Obstet Gynecol 2011;205(1):10-18. https://doi. A systematic review of the
org/10.1016/j.ajog.2010.12.033

11. Koegelenberg CFN, Irusen EM, Cooper R, et al. High mortality from respiratory failure secondary to swine-origin influenza A (H1N1) in South Africa. Q J Med 2010;103(5):319-325. https://doi. org/10.1093/qjmed/hcq022

12. Zambrano LD, Ellington S, Strid P, et al. Update: Characteristics of symptomatic women of reproductive age with laboratory-confirmed SARS-CoV-2 infection by pregnancy status - United States, January 22 - October 3, 2020. MMWR Morb Mortal Wkly Rep 2020;69(44):1641-1647. https:// doi.org/10.15585/mmwr.mm6944e3

13. Western Cape Government. Tygerberg Hospital - Annual Reports: 2016. https://www.westerncape. gov.za/your_gov/153/documents/annual_reports/2016 (accessed 20 November 2020).

14. National Department of Health, South Africa. Guidelines for maternity care in South Africa. 4th ed. 2015. https://health-e.org.za/2015/11/17/guidelines-maternity-care-in-south-africa/ (accessed 10 November 2020)

15. National Department of Health, South Africa. Guideline for the prevention of mother to child transmission of communicable infections. 2019. https://www.knowledgehub.org.za/elibrary/guidelinetransmission of communicable infections. 2019. https:// www.knowledgehub.org.za/elibrary/guidel

16. National Department of Health, South Africa. National consolidated guidelines for the prevention of mother-to-child transmission of HIV (PMTCT) and the management of HIV in children, adolescents
montion mother-to-child transmission of HIV (PMTCT) and the management of HIV in children, adolescents
and adults. 2014. https://www.knowledgehub.org.za/system/files/elibdownloads/2019-07/National\%2 and adults. 2014. https://www.knowledgehub.org.za/system/files/elibdownloads/

17. Van der Merwe TA, van Zyl GU, Lombard CJ, Theron GB. Intrapartum human immunodeficienc virus transmission rate in a central hospital in the Western Cape province after universal antiretroviral therapy roll-out. S Afr J Infect Dis 2020;35(1):a192. https://doi.org/10.4102/sajid.v35i1.192

18. Harris PA, Taylor R, Thielke R, Payne J, Gonzalez N, Conde JC. Research electronic data capture (REDCap) - A metadata-driven methodology and workflow process for providing translational research informatics support. J Biomed Inform 2009;42(2):377-381. https://doi.org/10.1016/j. jbi.2008.08.010

19. Harris PA, Taylor R, Minor BL, et al; on behalf of the REDCap Consortium. The REDCap consortium: Building an international community of software partners. J Biomed Inform 2019;95:103208. https:// doi.org/10.1016/j.jbi.2019.103208

20. World Health Organization. Regional Office for Europe. Definitions and indicators in family planning maternal \& child health and reproductive health used in the WHO Regional Office for Europe. Copenhagen: WHO Regional Office for Europe, 2000. https://apps.who.int/iris/handle/10665/108284 Copenhagen: WHO Regional
(accessed 10 November 2020).

21. National Institutes of Health. COVID-19 Treatment Guideline Panel. Coronavirus Disease 2019 (COVID-19) treatment guidelines. 2020. https://www.covid19treatmentguidelines.nih.gov/ (accessed 23 December 2020)

22. Badr DA, Mattern J, Carlin A, et al. Are clinical outcomes worse for pregnant women at $\geq 20$ weeks gestation infected with coronavirus disease 2019? A multicenter case-control study with propensity score matching. Am J Obstet Gynecol 2020;223(5):764-768. https://doi.org/10.1016/j.ajog.2020.07.045

23. Pastick KA, Nicol MR, Smyth E, et al. A systematic review of treatment and outcomes of pregnan women with COVID-19 - a call for clinical trials. Open Forum Infect Dis 2020;7(9):1-8. https://doi. org/10.1093/ofid/ofaa350

24. Delahoy MJ, Whitaker M, Chai SJ, et al. Characteristics and maternal and birth outcomes of hospitalised pregnant women with laboratory-confirmed COVID-19-COVID-NET, 13 states, March 1 - August 22, 2020. MMWR Morb Mortal Wkly Rep 2020;69(38):1347-1354. https://doi.org/10.15585/ - August 22, 2020

25. Blitz MJ, Rochelson B, Minkoff $\mathrm{H}$, et al. Maternal mortality among women with coronavirus disease 2019 admitted to the intensive care unit. Am J Obstet Gynecol 2020:223(4):595-599.e5. https://doi org/10.1016/.j.ajog.2020.06.020

26. Nakamura-Pereira M, Andreucci C, Menezes M, Knobel R, Takemoto MLS. Worldwide materna deaths due to COVID-19: A brief review. Int J Gynecol Obstet 2020;151(1):148-150. https://doi org/10.1002/ijgo.13328

27. Joint United Nations Programme on HIV and AIDS (UNAIDS). Country factsheets: South Africa 2019 HIV and AIDS estimates. 2019. https://www.unaids.org/en/regionscountries/countries/ southafrica (accessed 26 December 2020).

28. Nachega JB, Sam-Agudu NA, Budhram S, et al. Effect of SARS-CoV-2 infection in pregnancy on maternal and neonatal outcomes in Africa: An AFREhealth call for evidence through multicountr research collaboration. Am J Trop Med Hyg 2021:104(2):461-465. https://doi.org/10.4269/ ajtmh.20-1553

29. Kidney Disease: Improving Global Outcomes (KDIGO) Acute Kidney Injury Work Group. KDIGO clinical practice guideline for acute kidney injury. Kidney Int Suppl 2012;2:1-138. https://doi. org/10.1038/kisup.2012.3

Accepted 5 October 2021 